\title{
Teaching Mode of Thinking Development Learning Based on Mind Mapping in the Course of Health Fitness Education
}

\author{
https://doi.org/10.3991/ijet.v14i07.10110 \\ Jun Luo \\ Yunnan Vocational Institute of Energy Technology, Qujing, China \\ m18987432886@163.com
}

\begin{abstract}
The objective of thinking development lesson is to help students change and develop thoughts via classroom teaching. In thinking development lessons, students will reinforce the application scenarios of their thinking skills and learn new thinking skills. For design of classroom teaching of thinking development type, thinking visualization tools are needed for organizing and guiding thinking process. In this study, a teaching design framework of thinking development lesson was developed based on mind mapping, and applied in the teaching design process of the course of Health Fitness Education. It consists of five steps, namely teaching objective setting, question situation establishment, externalization of tacit thinking, formalization of explicit thinking, and automation of efficient thinking. Teaching result check shows that the course teaching design scheme developed in this study is helpful to improve students' learning effect in the course of Health Fitness Education significantly. This study provides a new teaching design method for teaching of Health Fitness Education, which is of important significance to helping students integrate the knowledge they have learned and rationalize thinking.
\end{abstract}

Keywords-Mind mapping; Thinking development learning; Health Fitness Education; Teaching mode

\section{Introduction}

With the continuous advancement of course teaching reform in each stage in China, the main teaching objective is gradually changing from training of knowledge and skills to training of ability and literacy. Students' ability and literacy relate to multiple aspects, and students are supposed to meet different requirements in different education phases for different subjects. Nevertheless, thinking ability training always occupies an important place in all education phases and subjects. Thus, the application of teaching for thinking in course design and classroom teaching has gained extensive attention [1]. Teaching for thinking refers to that the ultimate goal of course teaching is to help students' thinking ability development, and the main measure for realizing teaching for thinking is to combine thinking training with classroom teaching 
organically. The objective of thinking development lesson is to help students change and develop thoughts via classroom teaching [2]. In thinking development lessons, students will reinforce the application scenarios of their thinking skills and learn new thinking skills [3]. The core of design of thinking development classroom teaching is to organize and guide students' thinking development process efficiently. Thinking visualization tools often are needed to realize this process. Mind mapping [3] is a common means of teaching expression in teaching for thinking, and a visualization tool widely applied in externalization of tacit thinking. It is a chart for visually organizing information and presenting the relationships among the parts of an entirety in a layered way. It is usually created for a single concept by drawing a map in the centre of a blank page and adding related expressions of thoughts such as image, words, and partial words [4]. Yuliani et al. [5] applied thinking development learning in mathematical education in Islamic college. This study was a research development conducted in two stages. The first stage was to develop learning devices with the guided discovery method with reference Four-D model, and the second was try-out of learning package. Research results show that the learning method is helpful to raise students' learning interest. Hayes et al. [6] applied thinking development learning in interior design teaching. 139 beginners, intermediate and advanced interior design and architecture students were empirically assessed for the measure of intellectual development, designing measure, and learning style inventory respectively. Researches show that thinking development learning is of higher efficiency than traditional learning is. Aukes [7] combined experiential learning with thinking development learning and applied it in medical education. In this study, a pre post-test follow-up design was focused on, and comparison of the level of personal reflection ability was made between an exposure group of first-year medical students participating in a new enhanced experiential learning program and a control group of second and third year medical students participating in a standard problem-based learning program. Researches show that the learning method of the experimental group has positive impact on students' personal reflection ability.

Health fitness is one of the main contents of university physical education, and public physical education class, combat training, and life-saving training all relate to health fitness [8]. Therefore, studying and innovating teaching method, improving teaching efficiency of health fitness education, and enhancing students' internalization of knowledge and skills are topics that teachers of public security colleges must focus on. However, it is pointed out in some researches that the teaching of Health Fitness Education in colleges is not satisfactory in the following aspects. The first aspect is teaching content and mode. Since the teaching area of this subject is wide, it is really hard to achieve the desired teaching effect within the scheduled class hours [9]. Thus, the traditional "duck-stuffing" teaching mode is adopted in most schools, and it is difficult for students to interest in learning. The second aspect is about teaching method and means. For experiment teaching of health fitness education, the "duckstuffing" teaching method is adopted in most schools, so that teachers don't play a leading role, students don't occupy a dominant position, and students' initiative and enthusiasm are not aroused [10]. Thinking development classroom teaching is a teaching method for training students' thinking as the core. Thus, thinking 
development classroom teaching is applied in the teaching of Health Fitness Education in this study for trial. In the teaching of Health Fitness Education in this study, a new teaching method was designed based on thinking development learning of mind mapping, which is of important significance to helping students integrate the knowledge they have learned and rationalize thinking. This study was conducted to provide new ideas and reference for related educational reform of hygienics.

\section{State of the Art}

The theoretical basis for the thinking development learning curriculum in this study is model theory. Model theory is an effective tool and carrier for implementing thinking process, and can help people instantiate thinking process and content to improve the efficiency of thinking and logical reasoning. The process of model building essentially is a process of constantly exploring problems to finally solve the problems. The essence of thinking development learning based on mind mapping is to guide students to think so as to acquire knowledge and improve ability in teaching. Thus, the theory of model building is the basis for teaching design of thinking development lesson based on mind mapping.

Beanland et al. [11] conducted in-depth study on the theory of model building, and proposed a basic framework of model building, as shown in Fig. 1. In the framework, the whole process of model building consists of five links.

- Setting of objective of model building: Before model building, the problems to be solved by model building should be figured out first, which will guide the whole process.

- Information acquisition and model building: Next, it is necessary to obtain the type, source and acquiring channel of needed information for model building, select source of model and experience information needed for model building, and preliminarily develop a thinking model on this basis.

- Model description: The next step is to describe the model in a normative form and instantiate the model. The following job is to verify the rationality of the model. If the rationality does not conform to the requirements, a new source of model should be selected. Meanwhile, if the model is found to be unreasonable in the process of model description, corrections should be made without delay.

- Model verification: This link is to design and implement replication experiment to verify the rationality of model, and determine whether the preset objectives of model building are reached by collecting, collating and analyzing experimental data.

- Model Analysis: After rationality verification, it is needed to determine application scenarios and scope of model, and analyze limitations of model, so as to improve the whole model. 


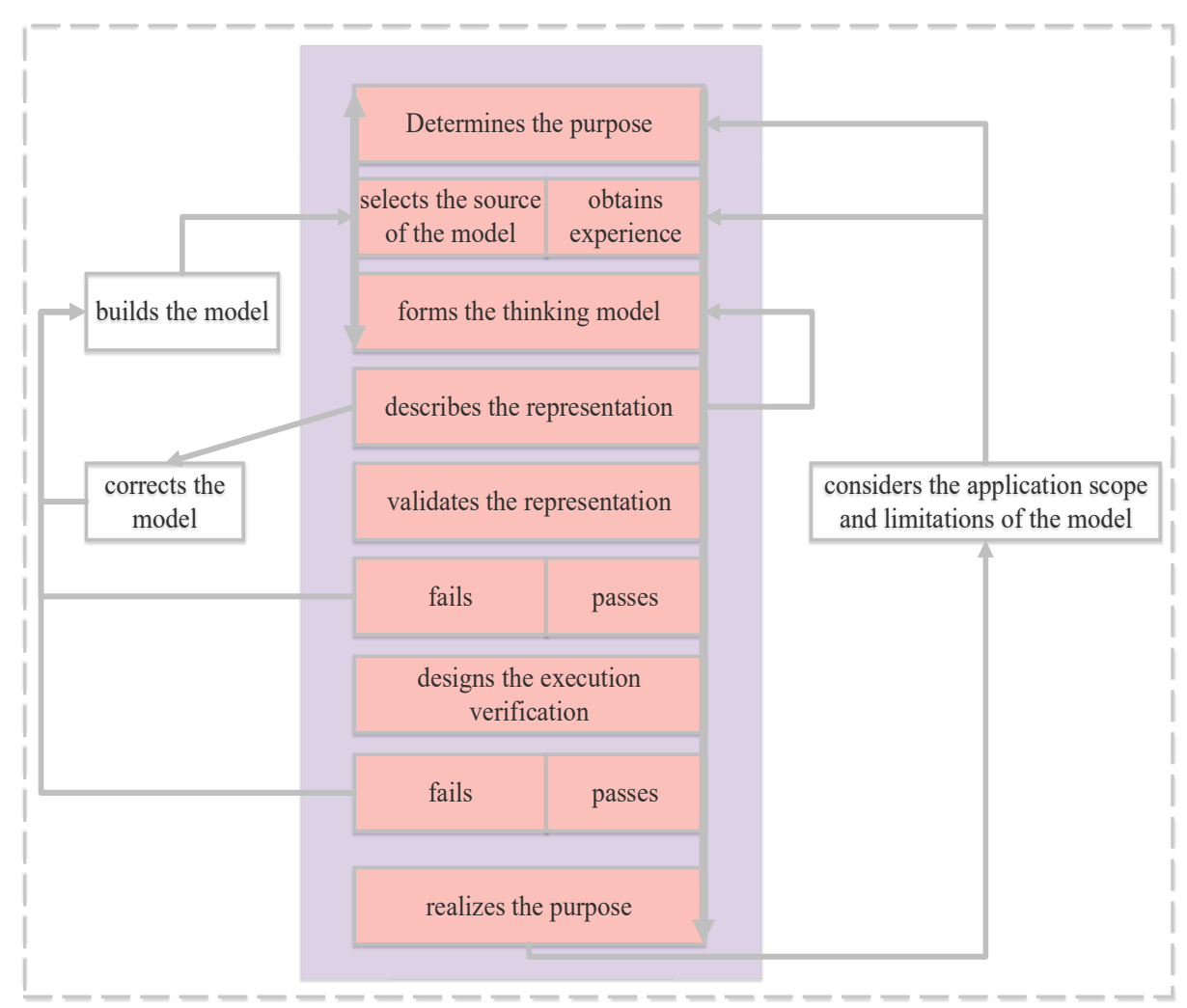

Fig. 1. Basic framework of model building proposed by Rosaria

Wang improved the process of model building based on Rosaria's researches, and determined an optimized model building process, as shown in Fig.2. The model building process consists of three modules, namely information collection, modeling, and simulation.

- Information collection: The main task of information collection is to identify and define problems to be solved, and investigate the theoretical background of problems, so as to determine and collect materials required for model building process.

- Modeling: Modeling is a core link of model building, and a process from question raising to question understanding.

- Simulation: The simulation link is to solve problems with the built model, which is a process from question understanding to question answering. If simulation result fails to reach the objective of model building, model discussion and model improvement are required so as to correct the model. 


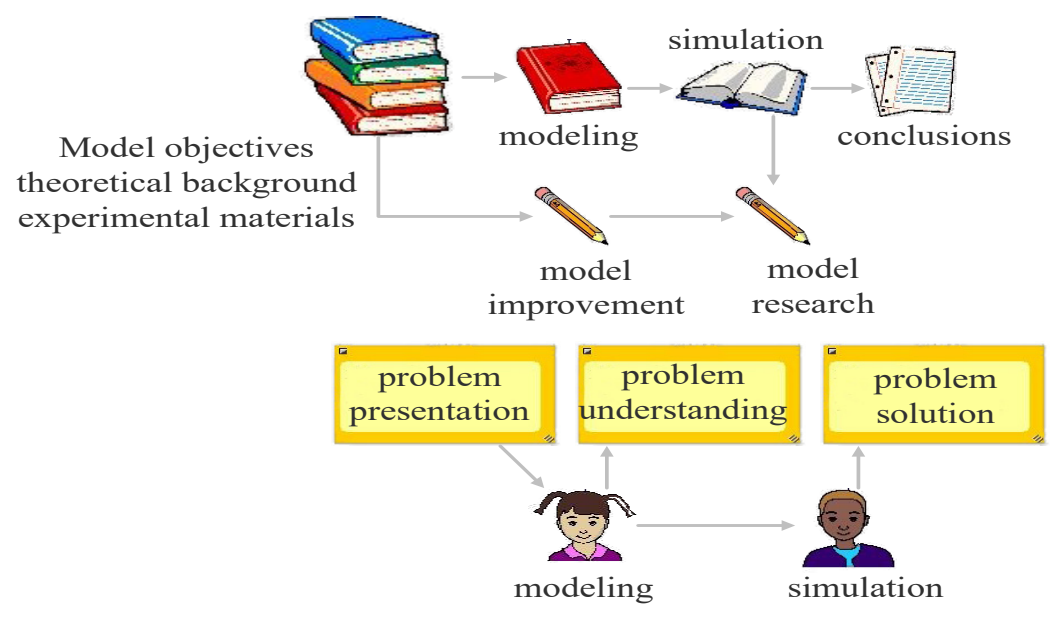

Fig. 2. Improved framework of model improvement

\section{Teaching Mode Design of Thinking Development Learning Based on Mind Mapping in the Course of Health Fitness Education}

Teaching design of thinking development learning is based on variant teaching. Variant teaching is a concrete form of learning transfer theory, and is classified into conceptual variant and procedural variant. Conceptual variant teaching is to teach concepts in a certain field from multiple angles to reinforce students' mastering and understanding. Procedural variant teaching is to help students enhance experience in a certain field via layered activities, which stresses changing teaching process from concept teaching to activity experience teaching to promote students' knowledge transfer. The theoretical framework of variant teaching method is as shown in Fig. 3.

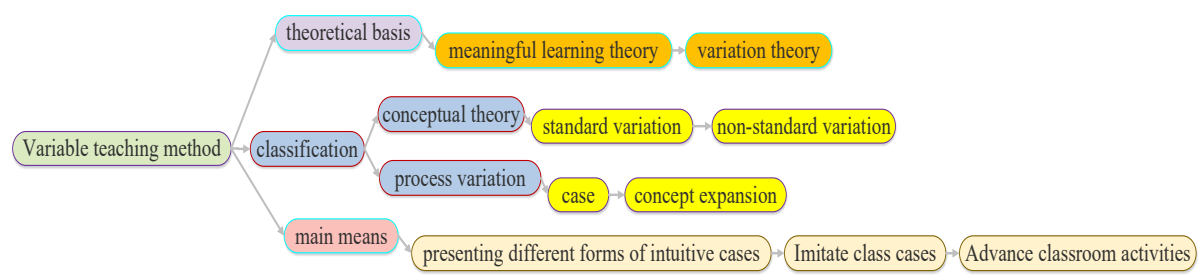

Fig. 3. Theoretical framework of variant teaching method

According to Fig. 3, variant teaching method is an effective means of teaching for thinking, and works well in promoting transfer of thinking skills [12]. In teaching design of thinking development lesson, variant teaching method is applied to promote students' thinking level, as below: 
- Conceptual variant is applied to promote students' learning of thinking skills and methods, so as to help students' master the usage and basic procedure of thinking skills and methods.

- Students are taught to solve problems with thinking skills and methods, and procedural variant teaching is applied to help students realize transfer of thinking skills and methods among different application scenarios to improve practical ability.

To apply thinking development learning based on mind mapping in lesson design of the course of Health Fitness Education, a five-step teaching method of thinking development lesson was designed in this study. The five steps are:

- Teaching objective setting

- Question situation establishment

- Externalization of tacit thinking

- Formalization of explicit thinking

- Automation of efficient thinking

\subsection{Teaching objective setting}

Teaching objective setting is the essential link of classroom teaching design, and the common principle to be complied with in the design of all subsequent links. Teaching objectives relate to the type and degree of students development in respect of knowledge and ability to be realized via classroom teaching. By cognitive objectives natural world of human being, teaching objectives are divided into six layers, namely extract, comprehension, application, analysis, evaluation and creation. In the process of teaching objective setting, teachers are supposed to set different hierarchies of objectives for different contents in combination with the practical situation of teaching module. The setting and definition of teaching objectives are helpful to design lesson straightforward, so as to avoid fragmentation of classroom teaching.

\subsection{Question situation establishment}

Traditional teaching method is of "duck-stuffing" form, in which knowledge is infused to students without consideration of students' receptivity, so that students are not initiative enough in learning. In thinking development lesson, it is stressed to put students in concrete scenarios for learning and reach teaching objectives by interacting with scenarios. In situation establishment link, teaching objectives should be decomposed to determine concrete teaching problems, and different teaching scenarios are to be established on the ground of the teaching problems [6]. Students are guided to develop thinking and master knowledge by means of developing and shifting among different scenarios. For question situation establishment, three principles should be complied with: 
- Question situation establishment should be based on students' cognitive level, and should not be lower or higher than students' cognitive level. Otherwise, students' anticipation of teaching objectives will be influenced, and adverse effect will be exerted on the whole learning process.

- Question situation establishment should be specific to teaching objectives only, and serve the realization of teaching objectives. The concrete teaching objective for which a situation is to be established and the functions of the situation should be defined.

- Question situation establishment should fully associate with students' life and learning, so as to promote students' ability and degree of participation in situation. This will promote the realization of teaching objectives.

\subsection{Externalization of tacit thinking}

Externalization of tacit thinking refers to instantiation of thinking process by the aid of visualization tools, to realize effective organize of thinking and knowledge. Fragmentation of knowledge and thinking is one of the main barriers in students' learning, which makes it hard for students' to systematize knowledge and thinking. Visualization tools are helpful for users to organize thinking and knowledge and strengthen their understanding of knowledge in organizing process. Concerning the teaching design framework of thinking development lesson constructed in this study, mind mapping was adopted as visualization tool to realize externalization of tacit thinking. Mind mapping is usually for presenting the relationships of parts of an entirety focusing on a certain single concept in layered way. Fig. 4 shows two examples of mind mapping, which realize externalization of tacit thinking in respect of characteristics of mind mapping and functions of mind mapping respectively.

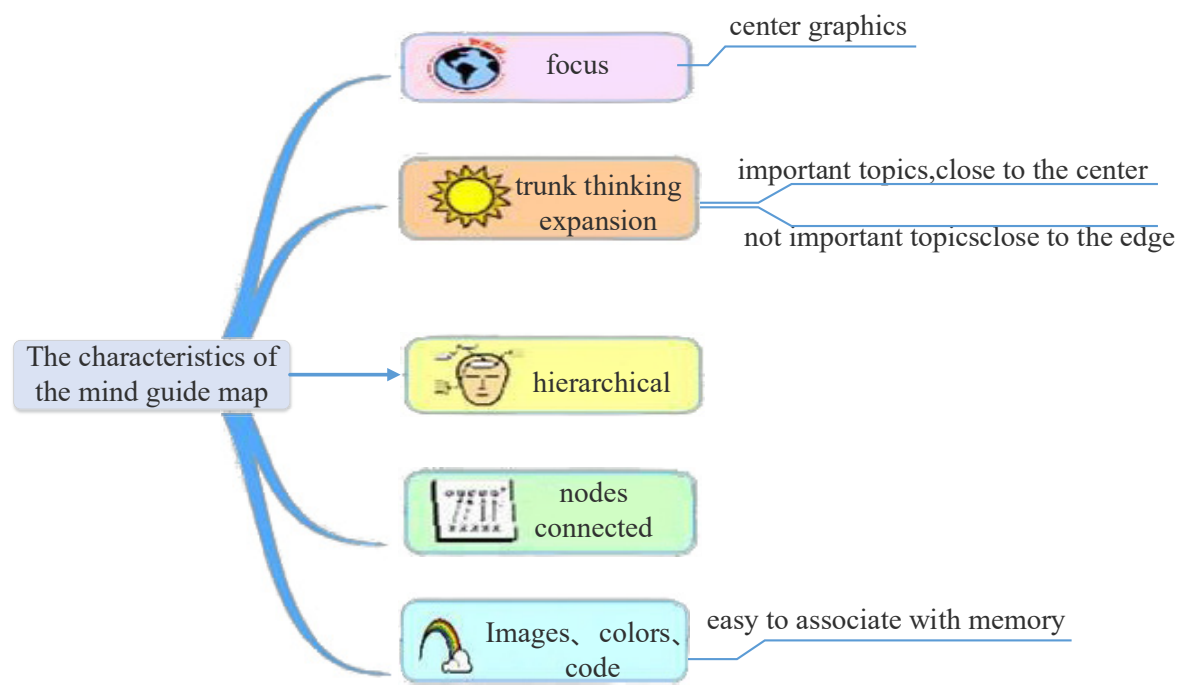

Fig. 4. Mind mapping example (I) 


\subsection{Formalization of explicit thinking}

The purpose of formalization of explicit thinking is to review thinking process with mind mapping constructed in the last link as tool, to identify the deficiencies and defects of the whole system. In this link, actions will be taken to break the destructive thinking patterns and limitations of conventional thinking with the aid of mind mapping, to realize thinking development. This study supports linux and xmind. Please see Figs. 5 for steps of software downloading and installation.

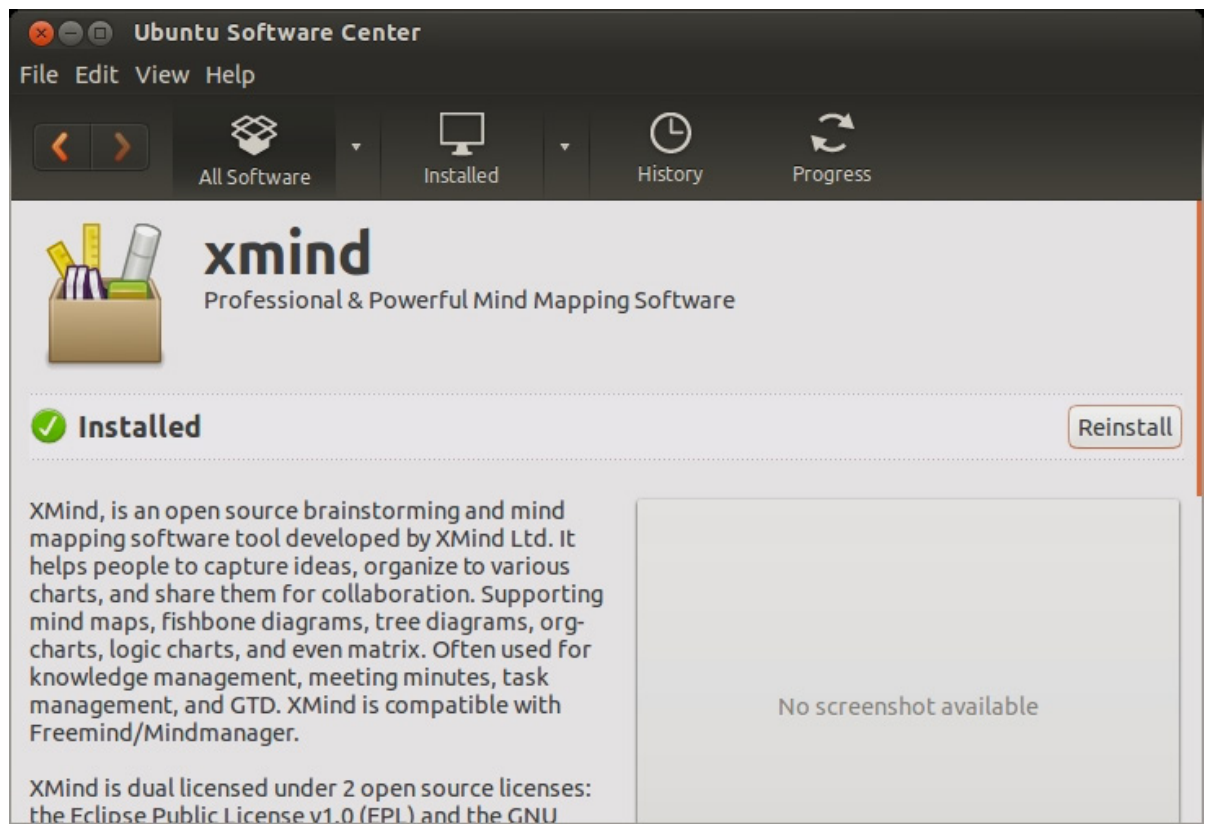

Fig. 5. Interface of installation completion of mind mapping software

\subsection{Automation of efficient thinking}

The purpose of automation of efficient thinking is to promote students' transfer of knowledge and ability in reliance upon variant teaching method, to improve students' level and ability of applying the learned knowledge. In this process, two variant teaching methods are available, which are applicable for different scenarios and have different functions.

- Conceptual variant: Conceptual variant is applied to promote students' learning of thinking skills and methods, so as to help students' master the usage and basic procedure of thinking skills and methods.

- Procedural variant: Students are taught to solve problems with thinking skills and methods, and procedural variant teaching is applied to help students realize transfer of thinking skills and methods among different application scenarios to improve practical ability. 


\subsection{Effect evaluation design of thinking development learning based on mind mapping}

Teaching evaluation is helpful for guiding, controlling and testing software teaching. There are many evaluation methods. For purpose of this study, the evaluation index system method was adopted to evaluate the effect of teaching software. Specifically, after try-out of the teaching software in multimedia network teaching system, users were asked to score the teaching software, and the data was collected, as shown in Table 1.

Table 1. Effect evaluation of thinking development learning based on mind mapping

\begin{tabular}{|c|c|c|c|c|c|c|}
\hline \multirow{2}{*}{\begin{tabular}{|c|}
$\begin{array}{c}\text { Structure } \\
\text { index }\end{array}$ \\
\end{tabular}} & \multirow[b]{2}{*}{ Single index } & \multicolumn{5}{|c|}{ Evaluation criteria (weight, grade and score) } \\
\hline & & Weight & Excellent & Good & Average & $\begin{array}{c}\text { Barely } \\
\text { satisfactory }\end{array}$ \\
\hline \multirow{6}{*}{\begin{tabular}{|l} 
Teaching \\
effect (40)
\end{tabular}} & $\begin{array}{l}\text { Accurate } \\
\text { expression of } \\
\text { teaching } \\
\text { content }\end{array}$ & 2 & $4-3$ & $3-2$ & $2-1$ & $1-0$ \\
\hline & \begin{tabular}{|l|} 
Definite \\
teaching \\
objectives
\end{tabular} & 2 & & & & \\
\hline & $\begin{array}{l}\text { Personal } \\
\text { tutoring }\end{array}$ & 2 & & & & \\
\hline & \begin{tabular}{|l}
$\begin{array}{l}\text { Collaborative } \\
\text { learning }\end{array}$ \\
\end{tabular} & 1 & & & & \\
\hline & \begin{tabular}{|l|} 
Promoting \\
knowledge \\
construction
\end{tabular} & 2 & & & & \\
\hline & \begin{tabular}{|l|} 
Flexible \\
teaching \\
strategy
\end{tabular} & 1 & & & & \\
\hline \multirow{5}{*}{$\begin{array}{l}\text { Technical } \\
\text { characteristics } \\
(40)\end{array}$} & $\begin{array}{l}\text { System } \\
\text { requirements }\end{array}$ & 2 & & & & \\
\hline & Reliability & 2 & & & & \\
\hline & \begin{tabular}{|l|} 
Internal- \\
external \\
interaction, \\
rational \\
interlinkage \\
\end{tabular} & 2 & & & & \\
\hline & \begin{tabular}{|l|} 
Process \\
control
\end{tabular} & 2 & & & & \\
\hline & \begin{tabular}{|l|} 
Easy operation \\
\end{tabular} & 2 & & & & \\
\hline \multirow{2}{*}{$\begin{array}{l}\text { Media } \\
\text { utilization (20) }\end{array}$} & $\begin{array}{l}\text { Information } \\
\text { presentation }\end{array}$ & 3 & & & & \\
\hline & $\begin{array}{l}\text { Media } \\
\text { combination }\end{array}$ & 2 & & & & \\
\hline Total & & & & & & \\
\hline
\end{tabular}

After the data was confirmed to be valid, information and data were quantitatively processed. The data values include teachers using software and students using software, and the analysis results were quantified. 


\section{Teaching Example and Teaching Effect}

\subsection{Teaching example}

To check the application effect of teaching design of thinking development lesson based on mind mapping, teaching design was developed for cardio-pulmonary resuscitation module of Health Fitness Education in this study, and applied in real teaching to check the effect. The teaching design process of cardio-pulmonary resuscitation module complies with the basic framework of thinking development lesson.

Teaching objective setting: In accordance with course outline and practice requirements of health fitness education, the teaching objectives of cardio-pulmonary resuscitation module cover three aspects: To understand fundamental principle and functions of cardio-pulmonary resuscitation; To accurately judge applicable scene of cardio-pulmonary resuscitation; To master basic procedure and skillfully use cardiopulmonary resuscitation.

Question situation establishment: The teaching of cardio-pulmonary resuscitation module covers both theory and practice, requiring students to master the fundamental principle and essential points of operation of cardio-pulmonary resuscitation and accurately complete the whole process of cardio-pulmonary resuscitation. Based on the teaching objective setting of cardio-pulmonary resuscitation teaching module, four teaching situations were established as below: Watch live video of cardio-pulmonary resuscitation, and have group discussions. This situation aims to instruct students to figure out the occasion when cardio-pulmonary resuscitation should be operated and basic procedure of cardio-pulmonary resuscitation, and discuss and extract the results by group. Read books, and make comparison with the results obtained in the first step. This situation aims to instruct students to read principle and procedure of cardio-pulmonary resuscitation set forth in teaching materials, and refer to and correct the results obtained in the first step. Watch video of movement decomposition of cardio-pulmonary resuscitation. This situation aims to instruct students to review essential points of operation of cardio-pulmonary resuscitation, and draw the flow diagram of cardio-pulmonary resuscitation. Exercise. This situation aims to instruct students to exercise cardio-pulmonary resuscitation, so as to improve their operational capacity. In this step, two-member groups were built, and students were asked to practice the procedure of cardio-pulmonary resuscitation to their teammate.

Externalization of tacit thinking: After question situation establishment, it is needed to realize externalization of tacit thinking by the aid of visualization tools. The mind mapping of teaching design of cardio-pulmonary resuscitation constructed according to the question situations is as shown in Fig. 4-1. The whole teaching process combines theory teaching and practical operation, and enables students to learn and master knowledge and skills. Fig. 8 shows teaching design of cardiopulmonary resuscitation module based on thinking development learning proposed in this study. 


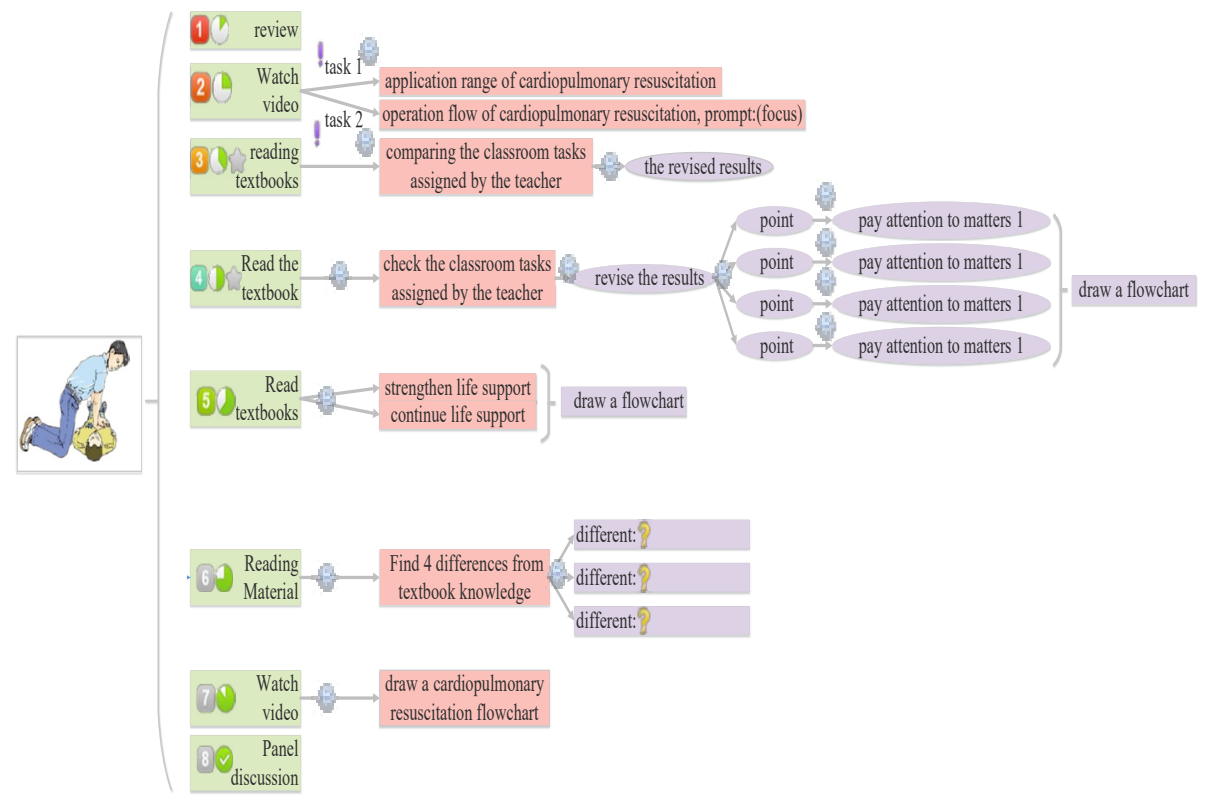

Fig. 6. Mind mapping of teaching design of cardio-pulmonary resuscitation module

Formalization of explicit thinking: The purpose of this link is to have students review and organize the learned knowledge and skills with the constructed mind mapping as the tool. According to the teaching objectives of cardio-pulmonary resuscitation module, students are required to organize the principle, functions, occasion and applicable scene of cardio-pulmonary resuscitation and extract key points and key words therefrom in knowledge system construction, which is helpful for deepening understanding and memory of knowledge and knowledge systematization. For construction of skill system, students are required to review the basic procedure of cardio-pulmonary resuscitation, draw a flow diagram of cardiopulmonary resuscitation, and summarize experience and lessons obtained from exercise by group.

Automation of efficient thinking: In the link of automation of efficient thinking, variant teaching method was applied to realize transfer of thinking ability. Conceptual variant teaching was adopted by pointing out the defects of several operation cases of cardio-pulmonary resuscitation in combination with the teaching requirements and objectives of cardio-pulmonary resuscitation module. Specifically, common errors in cardio-pulmonary resuscitation operation were presented with the combination of static diagram and animation, and students were asked to study the problems and put forward correction programs via group discussion. In procedural variant teaching, measures were taken to promote students' transfer of ability of using skills by simulation practice. Specifically, different situations were simulated, and students were asked to select a proper cardio-pulmonary resuscitation process. 


\subsection{Teaching effect}

To test the application effect of the thinking development learning method based on mind mapping in the course of Health Fitness Education, two 45-student classes were selected for teaching practice, with one class as the experimental group and the other as the control group. The thinking development learning method based on mind mapping was applied in the teaching process of the experimental group, and traditional teaching method was adopted for the control group. Teaching effect test was divided into two stages, namely pre-test and post-test. Same 100-score test papers were adopted for the two groups in all stages. The purpose of pre-test stage is to check whether there is significant difference between the experimental group and the control group in respect of the fundamental of Health Fitness Education. If there is no significant difference, it indicates that the two groups are feasible for application test of teaching effect. Post-test stage follows teaching practice to check how students have mastered the knowledge imparted in lesson.

The performance of the two groups in pre-test stage is shown in Table 2. The average score of the experimental group is 85 , with a standard deviation of 4.74; the average score of the control group is 86 , with a standard deviation of 4.73 . The difference in score between the two groups was subject to independent-sample T test, and the result indicates that there is no significant difference $(p>0.05)$.

Table 2. Descriptive statistics and independent-sample $T$ test of scores of experimental group and control group in pre-test stage

\begin{tabular}{|l|c|c|c|}
\hline \multicolumn{1}{|c|}{ Class } & Average value & Standard deviation & P value \\
\cline { 1 - 3 } Experimental group $(\mathrm{n}=45)$ & 78.32 & 9.02 & \multirow{2}{*}{0.623} \\
\hline Control group $(\mathrm{n}=45)$ & 78.65 & 9.31 & \\
\hline
\end{tabular}

The performance of the two groups in post-test stage is shown in Table 3. The average score of the experimental group is 85 , with a standard deviation of 4.74; the average score of the control group is 86 , with a standard deviation of 4.73. The difference in score between the two groups was subject to independent-sample T test, and the result indicates that there is significant difference $(p<0.05)$, and the score of the experimental group is significantly better than that of the control group. This shows that the application of thinking development learning based on mind mapping in teaching design of the course of Health Fitness Education is helpful to largely improve students' learning outcome.

Table 3. Descriptive statistics and independent-sample $T$ test of scores of experimental group and control group in post-test stage

\begin{tabular}{|l|c|c|c|}
\hline \multicolumn{1}{|c|}{ Class } & Average value & Standard deviation & P value \\
\cline { 1 - 2 } Experimental group $(\mathrm{n}=45)$ & 85.87 & 6.36 & \multirow{2}{*}{0.001} \\
\hline Control group $(\mathrm{n}=45)$ & 79.02 & 8.95 & \\
\hline
\end{tabular}




\section{Conclusion}

In thinking development lessons, students will reinforce the application scenarios of their thinking skills and learn new thinking skills. Based on the introduction to the basic principle and framework of model building, a teaching design framework of thinking development lesson was designed based on mind mapping in this study, which consists of teaching objective setting, question situation establishment, externalization of tacit thinking, formalization of explicit thinking, and automation of efficient thinking. The teaching design framework was applied in teaching design process of cardio-pulmonary resuscitation module of the course of Health Fitness Education, and the specific practice and contents of each step were stated. As to teaching effect check, analysis was made on scores of the experimental group and control group in pre-test and post-test, which indicates that the application of thinking development learning based on mind mapping in teaching design of the course of Health Fitness Education is helpful to improve students' learning outcome. This study provides a new teaching design method for teaching of Health Fitness Education, which is of important significance to helping students integrate the knowledge they have learned and rationalize thinking.

\section{References}

1. Gul, R., Cassum, S., Ahmad, A., et al. Enhancement of critical thinking in curriculum design and delivery: A randomized controlled trial for educators. Procedia - Social and Behavioral Sciences, 2010, vol. 2(2), pp. 3219-3225. https://doi.org/10. 1016/j.sbspro.2010.03.491

2. Hayes, K.D., Devitt, A.A. Classroom Discussions with Student-Led Feedback: a Useful Activity to Enhance Development of Critical Thinking Skills. Journal of Food Science Education, 2010, vol. 7(4), pp. 65-68. https://doi.org/10.1111/j.1541-4329.2008.00054.x

3. Gan, B.B., Daugulis, O. The development of inventive thinking skills in the upper secondary language classroom. Thinking Skills \& Creativity, 2008, vol. 3(1), pp. 34-46. https://doi.org/10.1016/j.tsc.2008.03.001

4. Davies, M. Concept mapping, mind mapping and argument mapping: what are the differences and do they matter?. Higher education, 2011, vol. 62(3), pp. 279-301. https://doi.org/10.1007/s10734-010-9387-6

5. Yuliani, K., \& Saragih, S. The Development of Learning Devices Based Guided Discovery Model to Improve Understanding Concept and Critical Thinking Mathematically Ability of Students at Islamic Junior High School of Medan. Journal of Education and Practice, 2015, vol. 6(24), pp. 116-128.

6. Hayes, K.D., Devitt, A.A. Classroom Discussions with Student-Led Feedback: a Useful Activity to Enhance Development of Critical Thinking Skills. Journal of Food Science Education, 2010, vol. 7(4), pp. 65-68. https://doi.org/10.1111/j.1541-4329.2008.00054.x

7. Aukes, L.C., Geertsma, J., Cohen-Schotanus, J., et al. The Effect of Enhanced Experiential Learning on the Personal Reflection of Undergraduate Medical Students. Medical Education Online, 2013, vol. 13(15), pp. 15. 
8. Liu, J.W., Shangguan, R.L., Keating, X.D., Leitner, J., \& Wu, Y.G. A conceptual physical education course and college freshmen's health-related fitness. Health Education, 2017, vol. 117(1), pp. 53-68. https://doi.org/10.1108/HE-01-2016-0002

9. Boyle, J., Mattern, C.O., Lassiter, J.W., et al. Peer 2 peer: efficacy of a course-based peer education intervention to increase physical activity among college students. Journal of American College Health J of Ach, 2011, vol. 59(6), pp. 519-529. https://doi.org/10. 1080/07448481.2010.523854

10. Keating, X.D., Wallace, J., Schafer, J., et al. Analyses of Higher Education Conceptual Physical Education Courses. ICHPER -- SD Journal of Research in Health, Physical Education, 2012, vol. 7(2), pp. 38-44.

11. Beanland, V., Fitzharris, M., Young, K. L., \& Lenné, M. G. Driver inattention and driver distraction in serious casualty crashes: data from the Australian national crash in-depth study. Accident Analysis \& Prevention, 2013, vol. 54(2), pp. 99-107. https://doi.org/10.1016/j.aap.2012.12.043

12. Zhou, Q., Ni, S., Hong, T. Developing critical thinking disposition by task-based learning in chemistry experiment teaching. Procedia - Social and Behavioral Sciences, 2010, vol. 2(2), pp. 4561-4570. https://doi.org/10.1016/j.sbspro.2010.03.731

\section{Author}

Jun Luo is a Lecturer in the Yunnan Vocational Institute of Energy Technology, Qujing, China Email id: (m18987432886@163.com).

Article submitted 2019-01-06. Resubmitted 2019-03-15. Final acceptance 2019-03-23. Final version published as submitted by the authors. 